OPEN ACCESS

Edited by:

Luca Paolo Ardigò

University of Verona, Italy

Reviewed by:

Vincenzo Rago,

Portuguese Football

Federation, Portugal

José María Oliva Lozano,

University of Almeria, Spain

*Correspondence:

Urs Granacher

urs.granacher@uni-potsdam.de

Hassane Zouhal

hassane.zouhal@univ-rennes2.fr

tORCID:

Urs Granacher

orcid.org/0000-0002-7095-813X

¥Present address:

Daniel Boullosa,

Sport and Exercise Science, James Cook University, Townsville, QLD, Australia; iLOAD Solutions, Brasilia,

Brazil

João Gustavo Claudino,

Research and Development

Department, LOAD CONTROL,

Contagem, Brazi

Specialty section

This article was submitted to

Exercise Physiology,

a section of the journal

Frontiers in Physiology

Received: 30 May 2020

Accepted: 22 July 2020

Published: 21 August 2020

Citation:

Boullosa D, Casado A, Claudino JG Jiménez-Reyes $P$, Ravé G,

Castaño-Zambudio A, Lima-Alves A

de Oliveira SA Jr, Dupont G

Granacher U and Zouhal H (2020) Do you Play or Do you Train? Insights

From Individual Sports for Training Load and Injury Risk Management in

Team Sports Based on

Individualization

Front. Physiol. 11:995.

doi: 10.3389/fphys.2020.00995

\section{Do you Play or Do you Train? Insights From Individual Sports for Training Load and Injury Risk Management in Team Sports Based on Individualization}

\author{
Daniel Boullosa ${ }^{1 \neq}$, Arturo Casado ${ }^{2}$, João Gustavo Claudino ${ }^{3 \ddagger}$, Pedro Jiménez-Reyes ${ }^{4}$, \\ Guillaume Ravé ${ }^{5}$, Adrián Castaño-Zambudio ${ }^{4}$, Adriano Lima-Alves ${ }^{6}$, \\ Silvio Assis de Oliveira Jr. ${ }^{1}$, Gregory Dupont ${ }^{7}$, Urs Granacher ${ }^{8 * t}$ and Hassane Zouhal ${ }^{9 *}$ \\ 1 Graduate Program of Movement Sciences, INISA, Federal University of Mato Grosso do Sul, Campo Grande, Brazil, \\ ${ }^{2}$ Faculty of Health Sciences, Isabel I University, Burgos, Spain, ${ }^{3}$ School of Physical Education and Sport, São Paulo \\ University, São Paulo, Brazil, ${ }^{4}$ Center for Sport Studies, Rey Juan Carlos University, Madrid, Spain, ${ }^{5}$ Toulouse Football Club, \\ Toulouse, France, ${ }^{6}$ Department of Sport Sciences, University Federal of Minas Gerais, Belo Horizonte, Brazil, ${ }^{7}$ Real Madrid \\ C.F, Madrid, Spain, ${ }^{8}$ Division of Training and Movement Sciences, University of Potsdam, Postdam, Germany, ${ }^{9}$ Department \\ of Sport Sciences, University of Rennes, Rennes, France
}

Keywords: training monitoring, injury prevention, physical fitness, acute:chronic workload ratio, periodization, sport physiology, evolutionary biology

\section{INTRODUCTION}

The understanding of the potential causes of musculoskeletal injuries in any competitive sport needs to address their multifactorial nature, which results from complex associations among different external conditions and modifiable and non-modifiable intrinsic risk factors (Drew and Purdam, 2016; Kalkhoven et al., 2020a). In this context, the cause of any non-contact injury merely results from a sum of loads generating a force that exceeds the limit supported by the respective biological tissue (Zernicke and Whiting, 2008). Consequently, it has been suggested that a poor load management is a major risk factor for injury in sport settings (Gabbett, 2016).

One novel monitoring tool for injury risk management is the acute: chronic workload ratio (ACWR). The ACWR is currently in the spot light of sport sciences (Griffin et al., 2020; Maupin et al., 2020). While some emerging evidence suggests that it is a valid method to identify an increased injury risk (Andrade et al., 2020), other authors have pointed out its methodological limitations and even questioned its validity (Impellizzeri et al., 2020; Wang et al., 2020). Proponents of the ACWR approach argue that athletes are at greater risk of sustaining a time-loss injury when the ACWR is higher relative to a lower or moderate ACWR (Andrade et al., 2020). In other words, the ACWR helps to identify critical windows in terms of elevated injury risk based on imbalanced training loading as for example sudden spike loads (Bowen et al., 2020).

The ACWR supposedly follows the classical fitness-fatigue model (Banister et al., 1975). Paradoxically, the rationale for the ACWR resides on several assumptions that are not in agreement with expected coaching practices as, for instance, progressive loading (Foster et al., 1995). Further, the occurrence of a sudden spike, in the context of any sport, could be simply interpreted as a training load error (Drew and Purdam, 2016; Kalkhoven et al., 2020b). In this respect, it is important to note that the ACWR literature includes mostly team sport studies, with the exception of a few studies in individual sports (Collette et al., 2018; Myers et al., 2020). For instance, a single study in swimming found the Acute Recovery and Stress Scale (ARSS) to be more valid than the ACWR to monitor recoverystress (Collette et al., 2018). In another recent study in junior tennis it was suggested that 
ACWR and injury history were the best predictors of injury incidence (Myers et al., 2020). It should be noted that tennis is an individual sport with the players directly interacting with each other, therefore it shares some mutual characteristics with most team sports. These mutual characteristics may include a number of contextual factors such as score line, match location, opposition standard, moment of the season, playing formation, player's role (Paul et al., 2015; Rago et al., 2019a; Curtis et al., 2020), and playing surface (Rago et al., 2019b; Vescovi and Falenchuk, 2019). For this reason, in this article we will refer to individual sports as those sports in which single athletes do not experience direct opposition from their opponents during competitions, with performances being strongly linked to physiological capacity (e.g., track and field or swimming). In this context, the limited number of ACWR studies in individual sports may be therefore not casual thus suggesting an inappropriate load management in some team sports under certain circumstances, probably related to the complexity associated to the existence of contextual factors which, in turn, would influence the physical and physiological profiles of team sport athletes.

Therefore, the aim of this opinion article is to provide a rationale based on coaching practices and scientific evidence from individual and team sports, that may help to better understand and, subsequently improve, training loads and injury risk management in team sports.

\section{DIFFERENCES IN PHYSIOLOGICAL DEMANDS BETWEEN INDIVIDUAL AND TEAM SPORTS}

The first consideration to be highlighted are differences in physiological demands between individual and team sports. While individual and team sports share some physiological attributes in common (Degens et al., 2019), it is noteworthy that individual sports need to maximize specific capacities (e.g., maximum oxygen consumption $\left[\mathrm{VO}_{2} \mathrm{max}\right]$, anaerobic threshold and economy in endurance sports) to be successful in competition. In team sports, athletes do not need to develop their maximal but optimal physiological attributes (e.g., $\mathrm{VO}_{2} \max$, muscle power) due to the multifactorial nature of performance determinants (e.g., technical skills, physical qualities, tactical behavior) that are ultimately decisive for success (Boullosa and Abreu, 2014). This differentiation is in agreement with the biological principle of allocation (Van Damme et al., 2002; Boullosa et al., 2013b) which, in turn, explains the important differences among sports that are evident when examining normative values of several physiological parameters (e.g., $\mathrm{VO}_{2}$ max in endurance athletes vs. soccer players) (Tønnessen et al., 2013; Sandbakk and Holmberg, 2017). Indeed, the need of maximizing specific physiological attributes in individual sports reveals a direct link between physiological characteristics and performance. This may explain why performance prediction works better with individual compared with team sports using data from physiological testing (Padilla et al., 2000; Esteve-Lanao et al., 2019).
Another important difference between individual vs. team sports refers to the competitive calendars which are often denser in team sports, with frequent competitions throughout the year (Nassis et al., 2020). In contrast, in individual sports, the competitive periods are generally shorter and allocated to specific periods (e.g., summertime) of the season (Costa et al., 2010). This important difference modulates two key loading events, namely peaking and tapering, which are directly linked to periodization models (Timpka et al., 2020). Thus, in individual sports, there are more prolonged periods (i.e., macrocycles) for loading before peaking, which usually occurs a few times over the year after important workload accumulation (Tønnessen et al., 2013). In team sports, a time-restricted workload accumulation normally occurs during the pre-season (Boullosa et al., 2013a) of the regular season, or during camps before tournaments (Noor et al., 2019). Therefore, there is no "true peaking" at any time of the season in team sports. Instead, there is a performance plateau on the level of physical and physiological adaptations that allows appropriate technical-tactical performances over time. These different loading patterns are also mirrored in tapering strategies. In individual sports, coaches frequently use tapering to reduce the workload before competition (Bosquet et al., 2007). In team sports, tapering is less pronounced and limited to some specific events during the season such as at the end of the pre-season or before an important match (Vachon et al., 2020). In this context, it seems important to postulate that the reduced loads on the days before matches in team sports cannot be considered as tapering. This weekly practices mostly reflect an attempt to recover sufficiently from matches, which is more evident in periods of congested match play (Saidi et al., 2019).

Another key point refers to the current understanding of the complex and self-correcting nature of the periodization process. That is, contrary to the static and fixed application of traditional periodization models, modern periodization approaches (Kiely, 2012 , 2018) are more based on the adaptation of training loads to the readiness and the levels of fatigue and fitness exhibited by the individual athlete. This type of periodization strategy affords different sources of data from the individual (e.g., heart rate, session rating of perceived exertion) and is adapted on a daily basis following biological principles (Kiely, 2012; Boullosa and Nakamura, 2013; Boullosa et al., 2013b). This is important to consider given that this level of individualization is mandatory in individual sports for success. In team sports, it is less common because training workloads are most often collectively performed, with predefined daily objectives included in the weekly microcycle. Furthermore, while traditional periodization approaches only consider the management of training and competitive workloads, a multifactorial approach has recently been suggested which includes more periodization components as recovery strategies, psychological skills, nutrition and skill acquisition (Mujika et al., 2018). All these periodization components are simultaneously manipulated to meet the desired short- and long-term adaptations of athletes.

The relationship between internal and external training loads (Impellizzeri et al., 2019) is a relevant difference between both types of sport (team vs. individual) which directly affects the quality of training monitoring. Thus, the relationship between 


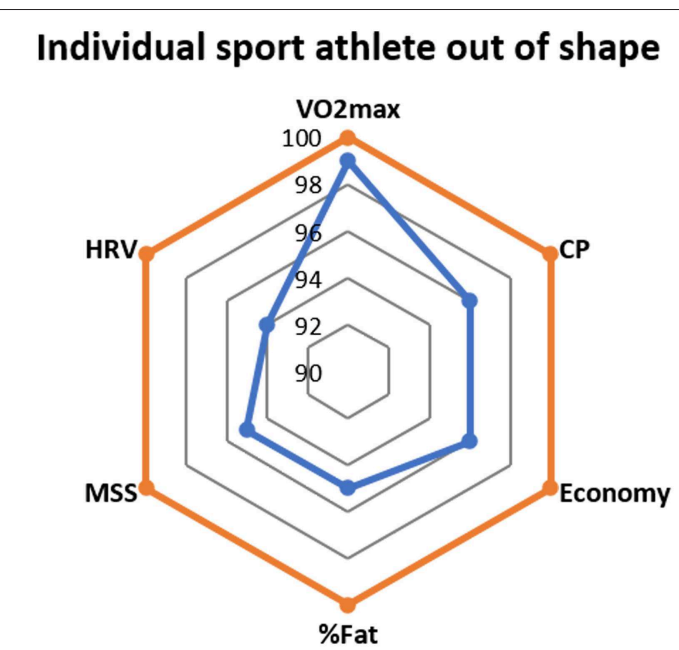

Team sport athlete out of shape

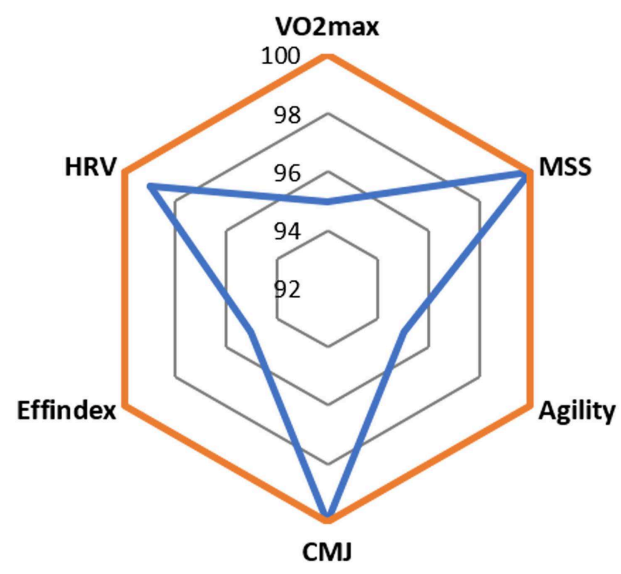

Individual sport athlete at optimal performance

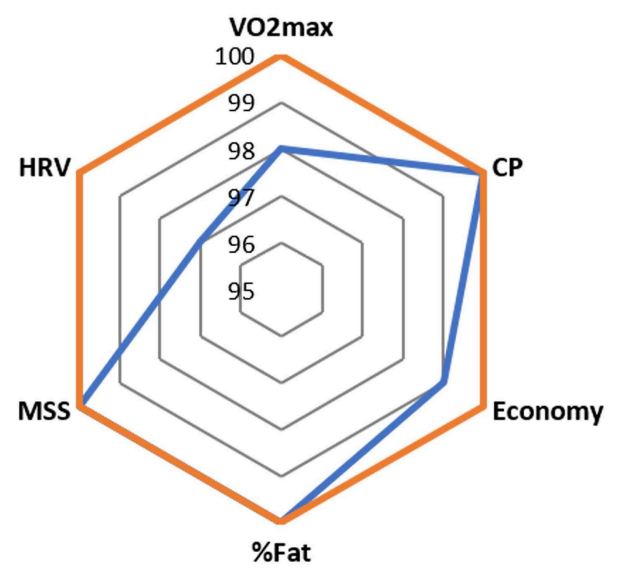

Team sport athlete at optimal performance

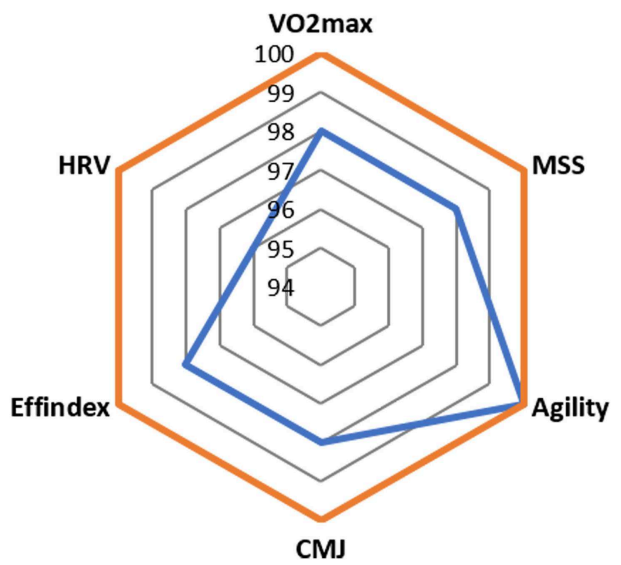

FIGURE 1 | Simulated example of the different evolution of physiological profiles in individual vs. team sports athletes. Note that in individual sports, most physiological parameters tend to be at their maximum individual values (personal best) at optimal performances. In contrast, this is not necessary for optimal performances in team sports. CMJ, countermovement jump; CP, critical power; Effindex, efficiency index; HRV, heart rate variability; MSS, maximum sprinting speed; $\mathrm{VO}_{2}$ max, maximum oxygen consumption; \%Fat, percentage of body fat.

internal and external loads is easier to monitor in individual sports because of their direct relationship (e.g., power or velocity vs. heart rate) (Boullosa et al., 2020). In team sports, it is more complicated because of the influence of contextual factors (Brito et al., 2016; Oliva-Lozano et al., 2020) affecting both internal and external load parameters in a different manner (Fox et al., 2020). The picture is even more complex if we consider that the current ACWR literature has found different relationships between ACWR indices generated with different internal [e.g., session rating of perceived exertion (sRPE)] and external (e.g., accelerations) load parameters in team sports characterized by different psycho-physiological demands (Andrade et al., 2020; Griffin et al., 2020). This means that the relationships found between ACWR and injury risk are not interchangeable among team sports, therefore suggesting the greater weight of extrinsic factors within this relationship, as it has been also suggested that the strength of the relationships between internal and external load parameters in team sports depends upon the training mode (McLaren et al., 2018).

\section{THE INDIVIDUALIZATION APPROACH IN TEAM SPORTS}

After having presented the main differences between individual and team sports, we suggest an individualized approach to better manage training loads in team sports which may help to reduce the likelihood of sustaining injuries and optimize performance. Thus, individualization is the key in a multifactorial periodization model. In other words, the individual response in terms of training and competitive workload, nutrition, psychological skills, recovery strategies, and skill acquisition, allows a more flexible periodization approach on a daily basis. Moreover, given that injury history of an individual is a relevant factor for the 
relationship between workloads and injury risk (Esmaeili et al., 2018), medical staff together with strength and conditioning coaches should collectively develop individualized preventive and therapeutic interventions for those players who suffered injuries in the past, with special attention to the context (Bolling et al., 2018).

Although a significant time of daily training in team sports is devoted to collective training, individualization of all these aspects would result in a better control of the fitness-fatigue relationship by avoiding any sudden workload spike and thus an increased injury risk. Further, as technological advances allow to monitor the individual player during collective training (e.g., measuring the number of accelerations during small sided games with GPS technologies), individualization of all the components of a multifactorial periodization during both individual and collective behaviors appears feasible (Li et al., 2016). However, the excess of information to be managed with this approach is extremely high, therefore the use of big data analysis through artificial intelligence is warranted (Claudino et al., 2019). This is especially true in big clubs, in which the different staff divisions need to better coordinate their work (e.g., medical staff, strength and conditioning specialists, physiotherapists, analysts, nutritionist, etc.) through fluent communication (Bolling et al., 2020) to successfully manage the individualization process. When gathering all these "objective" data, head coaches' expertise, and knowledge should not be ignored for decision making. However, head coaches must be prepared and well-supported by different staff divisions as the amount of data to be managed is continuously increasing, including the monitoring of daily living activities (Boullosa et al., 2013b; Düking et al., 2018; Izzicupo et al., 2019).

The major advantage of this individualized approach is that it avoids any excessive loading, and therefore sudden individual workload spikes. Accordingly, the ACWR could be simply used to confirm an inappropriate individual workload management which would never occur following this approach. This aspect is one key to better understand the questioned validity of the ACWR (Impellizzeri et al., 2020). Using this individualized monitoring approach, it is possible to prevent excessive fatigue, incomplete recovery or insufficient readiness associated with low fitness. Similarly, the potential uncoupling between selected internal and external workload parameters due to the influence of contextual factors during matches (Fox et al., 2020), can be better managed with the consideration of sport specific contextual factors (e.g., starters vs. non-starters) to better adapt selected periodization components (e.g., psychological skills, recovery strategies) and thus, to avoid any individual load imbalance. Meanwhile, it is still to be resolved if the identification of individual physiological profiles associated with optimal technical and tactical performances, would assist to better select individualized interventions to mimic these optimal

\section{REFERENCES}

Andrade, R., Wik, E. H., Rebelo-Marques, A., Blanch, P., Whiteley, R., EspregueiraMendes, J., et al. (2020). Is the acute: chronic workload ratio (ACWR) associated with risk of time-loss injury in professional team sports? A individual profiles throughout the season. This is contrary to the direct link between maximal physiological test performances and competitive performance outcomes in most individual sports. For instance, in team sports, maximal leg power is not necessarily linked with match performance (Tangalos et al., 2015). This is different with individual sports such as sprinting (Loturco et al., 2015). An example of this different evolution between physiological profiles in individual vs. team sports is shown in Figure 1.

There are a number of monitoring tools and parameters to assist in this individualization process such as aerobic power (Milanez et al., 2011), the end speed of the 30-15 intermittent fitness tests (Malone et al., 2018a; Grgic et al., 2020), the anaerobic speed reserve (Buchheit and Mendez-Villanueva, 2014), muscle power (Loturco et al., 2019), heart rate variability (Rave et al., 2018, 2019), countermovement jump performance (Claudino et al., 2012), the force-velocity profile (Mendiguchia et al., 2016), HR measures during specific drills (Lacome et al., 2018), wellbeing questionnaires (Malone et al., 2018b), or individualized training loads modeling (Bartlett et al., 2017) among others. Specific monitoring tools should be selected and adapted to each sport and setting while developing the athlete monitoring cycle (Gabbett et al., 2017). However, this process is incomplete if the periodization components are not simultaneously adapted to meet the desired individual adaptation of each athlete. Meanwhile, it needs to be solved if the individualization of some monitoring tools is really necessary (Scott and Lovell, 2018), or if it is simply a problem of signal-to-noise ratio (Boullosa and Abreu, 2014).

In summary, we have illustrated the main differences regarding workload management between individual and team sports, and how a true individualization of all the periodization factors in team sports could result in a better managed fitnessfatigue equilibrium and, thus, in a reduced injury risk and enhanced performance. Future studies should illustrate how this paradigm may induce better performances and health outcomes in team sport athletes.

\section{AUTHOR CONTRIBUTIONS}

DB conceived and designed the idea. All authors wrote, revised the manuscript draft, read, and approved the final manuscript version.

\section{FUNDING}

The authors acknowledge the support of the Deutsche Forschungsgemeinschaft (DFG) and Open Access Publishing Fund of the University of Potsdam, Germany. $\mathrm{DB}$ is granted with a productivity research grant from CNPq.

systematic review of methodology, variables and injury risk in practical situations. Sport. Med. doi: 10.1007/s40279-020-01308-6. [Epub ahead of print].

Banister, E. W., Calvert, T. W., Savage, M. V., and Bach, T. (1975). A systems model of the hfifects of training on physical perfoffnance. IEEE Trans. Syst. Man. Cybern. 6, 94-102. doi: 10.1109/TSMC.1976.5409179 
Bartlett, J. D., O'Connor, F., Pitchford, N., Torres-Ronda, L., and Robertson, S. J. (2017). Relationships between internal and external training load in team-sport athletes: evidence for an individualized approach. Int. J. Sports Physiol. Perform. 12, 230-234. doi: 10.1123/ijspp.2015-0791

Bolling, C., Delfino Barboza, S., Van Mechelen, W., and Pasman, H. R. (2020). Letting the cat out of the bag: athletes, coaches and physiotherapists share their perspectives on injury prevention in elite sports. Br. J. Sports Med. 54, 871-877. doi: 10.1136/bjsports-2019-100773

Bolling, C., van Mechelen, W., Pasman, H. R., and Verhagen, E. (2018). Context matters: revisiting the first step of the 'sequence of prevention' of sports injuries. Sport. Med. 48, 2227-2234. doi: 10.1007/s40279-018-0953-x

Bosquet, L., Montpetit, J., Arvisais, D., and Mujika, I. (2007). Effects of tapering on performance: a meta-analysis. Med. Sci. Sports Exerc. 39, 1358-1365. doi: $10.1249 / \mathrm{mss} .0 \mathrm{~b} 013 \mathrm{e} 31806010 \mathrm{e} 0$

Boullosa, D., Esteve-lanao, J., Casado, A., Peyr, L. A., Gomes, R., and Coso, J., Del (2020). Factors affecting training and physical performance in recreational endurance runners. Sports 8:35. doi: 10.3390/sports 8030035

Boullosa, D. A., and Abreu, L. (2014). Dr. Boullosa's forgotten pieces don't fit the puzzle: a response to Dr. Buchheit and Dr. Laursen. Sport. Med. 44, 1625-1628. doi: 10.1007/s40279-014-0271-x

Boullosa, D. A., Abreu, L., Nakamura, F. Y., Muñoz, V. E., Domínguez, E., and Leicht, A. S. (2013a). Cardiac autonomic adaptations in elite spanish soccer players during preseason. Int. J. Sports Physiol. Perform. 8, 400-409. doi: 10.1123/ijspp.8.4.400

Boullosa, D. A., Abreu, L., Varela-Sanz, A., and Mujika, I. (2013b). Do olympic athletes train as in the paleolithic era? Sport. Med. 43, 909-917. doi: 10.1007/s40279-013-0086-1

Boullosa, D. A., and Nakamura, F. Y. (2013). The evolutionary significance of fatigue. Front. Physiol. 4:309. doi: 10.3389/fphys.2013.00309

Bowen, L., Gross, A. S., Gimpel, M., Bruce-Low, S., and Li, F. X. (2020). Spikes in acute:chronic workload ratio (ACWR) associated with a 5-7 times greater injury rate in english premier league football players: a comprehensive 3-year study. Br. J. Sports Med. 54, 731-738. doi: 10.1136/bjsports-2018099422

Brito, J., Hertzog, M., and Nassis, G. P. (2016). Do match-related contextual variables influence training load in highly trained soccer players? J. Strength Cond. Res. 30, 393-399. doi: 10.1519/JSC.0000000000001113

Buchheit, M., and Mendez-Villanueva, A. (2014). Changes in repeated-sprint performance in relation to change in locomotor profile in highly-trained young soccer players. J. Sports Sci. 32, 1309-1317. doi: 10.1080/02640414.2014.918272

Claudino, J. G., Capanema, D., de, O., de Souza, T. V., Serrão, J. C., Machado Pereira, A. C., et al. (2019). Current approaches to the use of artificial intelligence for injury risk assessment and performance prediction in team sports: a systematic review. Sport. Med. Open 5:28. doi: 10.1186/s40798-019-0202-3

Claudino, J. G., Mezncio, B., Soncin, R., Ferreira, J. C., Couto, B. P., and Szmuchrowski, L. A. (2012). Pre vertical jump performance to regulate the training volume. Int. J. Sports Med. 33, 101-107. doi: 10.1055/s-0031-1286293

Collette, R., Kellmann, M., Ferrauti, A., Meyer, T., and Pfeiffer, M. (2018). Relation between training load and recovery-stress state in high-performance swimming. Front. Physiol. 9:845. doi: 10.3389/fphys.2018.00845

Costa, M. J., Marinho, D. A., Reis, V. M., Silva, A. J., Marques, M. C., Bragada, J. A., et al. (2010). Tracking the performance of world-ranked swimmers. J. Sports. Sci. Med. 9, 411-417.

Curtis, R. M., Huggins, R. A., Benjamin, C. L., Sekiguchi, Y., Adams, W. M., Arent, S. M., et al. (2020). Contextual factors influencing external and internal training loads in collegiate men's soccer. J. Strength Cond. Res. 34, 374-381. doi: 10.1519/JSC.0000000000003361

Degens, H., Stasiulis, A., Skurvydas, A., Statkeviciene, B., and Venckunas, T. (2019). Physiological comparison between non - athletes, endurance, power and team athletes. Eur. J. Appl. Physiol. 119, 1377-1386. doi: 10.1007/s00421-019-04128-3

Drew, M. K., and Purdam, C. (2016). Time to bin the term 'overuse' injury: is 'training load error' a more accurate term? Br. J. Sports Med. 50, 1423-1424. doi: 10.1136/bjsports-2015-095543

Düking, P., Achtzehn, S., Holmberg, H. C., and Sperlich, B. (2018). Integrated framework of load monitoring by a combination of smartphone applications, wearables and point-of-care testing provides feedback that allows individual responsive adjustments to activities of daily living. Sensors 18, 1-11. doi: 10.3390/s18051632

Esmaeili, A., Hopkins, W. G., Stewart, A. M., Elias, G. P., Lazarus, B. H., and Aughey, R. J. (2018). The individual and combined effects of multiple factors on the risk of soft tissue non-contact injuries in elite team sport athletes. Front. Physiol. 9:1280. doi: 10.3389/fphys.2018.01280

Esteve-Lanao, J., Del Rosso, S., Larumbe-Zabala, E., Cardona, C., Alcocer-Gamboa, A., and Boullosa, D. A. (2019). Predicting recreational runners' marathon performance time during their training preparation. J. Strength Cond. Res. doi: 10.1519/JSC.0000000000003199. [Epub ahead of print].

Foster, C., Hector, L. L., Welsh, R., Schrager, M., Green, M. A., and Snyder, A. C. (1995). Effects of specific versus cross-training on running performance. Eur. J. Appl. Physiol. Occup. Physiol. 70, 367-372. doi: 10.1007/BF00865035

Fox, J. L., Stanton, R., Sargent, C., O'Grady, C. J., and Scanlan, A. T. (2020). The impact of contextual factors on game demands in starting, semiprofessional, male basketball players. Int. J. Sports Physiol. Perform. 15, 450-456. doi: 10.1123/ijspp.2019-0203

Gabbett, T. J. (2016). The training-injury prevention paradox: should athletes be training smarter and harder? Br. J. Sports Med. 50, 273-280. doi: 10.1136/bjsports-2015-095788

Gabbett, T. J., Nassis, G. P., Oetter, E., Pretorius, J., Johnston, N., Medina, D., et al. (2017). The athlete monitoring cycle: a practical guide to interpreting and applying training monitoring data. Br. J. Sports Med. 51, 1451-1452. doi: 10.1136/bjsports-2016-097298

Grgic, J., Lazinica, B., and Pedisic, Z. (2020). Test-retest reliability of the 30-15 intermittent fitness test: a systematic review. J. Sport Health. Sci. doi: 10.1016/j.jshs.2020.04.010. [Epub ahead of print].

Griffin, A., Kenny, I. C., Comyns, T. M., and Lyons, M. (2020). The association between the acute:chronic workload ratio and injury and its application in team sports: a systematic review. Sport. Med. 50, 561-580. doi: 10.1007/s40279-019-01218-2

Impellizzeri, F. M., Marcora, S. M., and Coutts, A. J. (2019). Internal and external training load: 15 years on. Int. J. Sports Physiol. Perform. 14, 270-273. doi: 10.1123/ijspp.2018-0935

Impellizzeri, F. M., Tenan, M. S., Kempton, T., Novak, A., and Coutts, A. J. (2020). Acute:chronic workload ratio: conceptual issues and fundamental pitfalls. Int J. Sports Physiol. Perform. doi: 10.1123/ijspp.2019-0864. [Epub ahead of print].

Izzicupo, P., Di Baldassarre, A., Ghinassi, B., Reichert, F. F., Kokubun, E., and Nakamura, F. Y. (2019). Can off-training physical behaviors influence recovery in athletes? A scoping review. Front. Physiol. 10:448. doi: $10.3389 /$ fphys.2019.00448

Kalkhoven, J., Coutts, A. J., and Impellizzeri, F. M. (2020b). 'Training load error' is not a more accurate term than 'overuse' injury. Br. J. Sports Med. 54, 934-935. doi: 10.1136/bjsports-2019-101710

Kalkhoven, J. T., Watsford, M. L., and Impellizzeri, F. M. (2020a). A conceptual model and detailed framework for stress-related, strain-related, and overuse athletic injury. J. Sci. Med. Sport. 23, 726-734 doi: 10.1016/j.jsams.2020.02.002

Kiely, J. (2012). Periodization paradigms in the 21st century: evidenceled or tradition-driven? Int. J. Sports Physiol. Perform. 7, 242-250. doi: 10.1123 /ijspp.7.3.242

Kiely, J. (2018). Periodization theory: confronting an inconvenient truth. Sport. Med. 48, 753-764. doi: 10.1007/s40279-017-0823-y

Lacome, M., Simpson, B., Broad, N., and Buchheit, M. (2018). Monitoring players' readiness using predicted heart-rate responses to soccer drills. Int. J. Sports Physiol. Perform. 13, 1273-1280. doi: 10.1123/ijspp.2018-0026

Li, R. T., Kling, S. R., Salata, M. J., Cupp, S. A., Sheehan, J., and Voos, J. E. (2016). Wearable performance devices in sports medicine. Sports Health 8, 74-78. doi: $10.1177 / 1941738115616917$

Loturco, I., Pereira, L. A., Cal Abad, C. C., D’Angelo, R. A., Fernandes, V., Kitamura, K., et al. (2015). Vertical and horizontal jump tests are strongly associated with competitive performance in $100-\mathrm{m}$ dash events. J. Strength Cond. Res. 29, 1966-1971. doi: 10.1519/JSC.0000000000000849

Loturco, I., Pereira, L. A., Reis, V. P., Bishop, C., Zanetti, V., Alcaraz, P. E., et al. (2019). Power training in elite young soccer players: effects of using loads above or below the optimum power zone. J. Sports Sci. 38, 1416-1422. doi: 10.1080/02640414.2019.1651614

Malone, S., Owen, A., Mendes, B., Hughes, B., Collins, K., and Gabbett, T. J. (2018a). High-speed running and sprinting as an injury risk factor in soccer: 
can well-developed physical qualities reduce the risk? J. Sci. Med. Sport. 21, 257-262. doi: 10.1016/j.jsams.2017.05.016

Malone, S., Owen, A., Newton, M., Mendes, B., Tiernan, L., Hughes, B., et al. (2018b). Wellbeing perception and the impact on external training output among elite soccer players. J. Sci. Med. Sport 21, 29-34. doi: 10.1016/j.jsams.2017.03.019

Maupin, D., Schram, B., Canetti, E., and Orr, R. (2020). The relationship between acute: chronic workload ratios and injury risk in sports: a systematic review. Open Access J. Sport. Med. 11, 51-75. doi: 10.2147/OAJSM.S231405

McLaren, S. J., Macpherson, T. W., Coutts, A. J., Hurst, C., Spears, I. R., and Weston, M. (2018). The relationships between internal and external measures of training load and intensity in team sports: a meta-analysis. Sport. Med. 48, 641-658. doi: 10.1007/s40279-017-0830-Z

Mendiguchia, J., Edouard, P., Samozino, P., Brughelli, M., Cross, M., Ross, A., et al. (2016). Field monitoring of sprinting power-force-velocity profile before, during and after hamstring injury: two case reports. J. Sports Sci. 34, 535-541. doi: 10.1080/02640414.2015.1122207

Milanez, V. F., Pedro, R. E., Moreira, A., Boullosa, D. A., Salle-Neto, F., and Nakamura, F. Y. (2011). The role of aerobic fitness on session rating of perceived exertion in futsal players. Int. J. Sports Physiol. Perform. 6, 358-366. doi: 10.1123/ijspp.6.3.358

Mujika, I., Halson, S., Burke, L. M., Balagu,é, G., and Farrow, D. (2018). An integrated, multifactorial approach to periodization for optimal performance in individual and team sports. Int. J. Sports Physiol. Perform. 13, 538-561. doi: 10.1123/ijspp.2018-0093

Myers, N. L., Aguilar, K. V., Mexicano, G., Farnsworth, J. L., Knudson, D., and Kibler, W. B. (2020). The acute:chronic workload ratio is associated with injury in junior tennis players. Med. Sci. Sport. Exerc. 52, 1196-1200. doi: 10.1249/MSS.0000000000002215

Nassis, G. P., Massey, A., Jacobsen, P., Brito, J., Randers, M. B., Castagna, C., et al. (2020). Elite football of 2030 will not be the same as that of 2020: Preparing players, coaches, and support staff for the evolution. Scand. J. Med. Sci. Sport. 30, 962-964. doi: 10.1111/sms.13681

Noor, D., McCall, A., Jones, M., Duncan, C., Ehrmann, F., Meyer, T., et al. (2019). Transitioning from club to national teams: training and match load profiles of international footballers. J. Sci. Med. Sport. 22, 948-954. doi: 10.1016/j.jsams.2019.02.006

Oliva-Lozano, J. M., Rojas-Valverde, D., Gómez-Carmona, C. D., Fortes, V., and Pino-Ortega, J. (2020). Impact Of contextual variables on the representative external load profile of Spanish professional soccer matchplay: a full season study. Eur. J. Sport Sci. Epub Ahead of Print. doi: 10.1080/17461391.2020.1751305

Padilla, S., Mujika, I., Angulo, F., and Goiriena, J. J. (2000). Scientific approach to the 1-h cycling world record: a case study. J. Appl. Physiol. 89, 1522-1527. doi: 10.1152/jappl.2000.89.4.1522

Paul, D. J., Bradley, P. S., and Nassis, G. P. (2015). Factors affecting match running performance of elite soccer players: shedding some light on the complexity. Int. J. Sports Physiol. Perform. 10, 516-519. doi: 10.1123/ijspp.2015-0029

Rago, V., Rebelo, A., Krustrup, P., and Mohr, M. (2019a). Contextual variables and training load throughout a competitive period in a top-level male soccer team. J. Strength Cond. Res. doi: 10.1519/JSC.0000000000003258. [Epub ahead of print].

Rago, V., Silva, J. R., Brito, J., Barreira, D., Mohr, M., Krustrup, P., et al. (2019b). Switching between pitch surfaces: practical applications and future perspectives for soccer training. J. Sports Med. Phys. Fitness. 59, 510-519. doi: 10.23736/S0022-4707.18.08278-6

Rave, G., Fortrat, J. O., Dawson, B., Carre, F., Dupont, G., Saeidi, A., et al. (2018). Heart rate recovery and heart rate variability: use and relevance in European professional soccer. Int. J. Perform. Anal. Sport. 18, 168-183. doi: $10.1080 / 24748668.2018 .1460053$
Rave, G., Zohual, H., Boullosa, D., Doyle-Baker, P. K., Saeidi, A., Ben Abderrahman, A., et al. (2019). Heart rate variability is correlated with perceived physical fitness in elite soccer players Heart rate variability is correlated with perceived physical fitness in elite soccer players. J. Hum. Kinet. 72, 141-150. doi: 10.2478/hukin-2019-0103

Saidi, K., Zouhal, H., Rhibi, F., Tijani, J. M., Boullosa, D., Chebbi, A., et al. (2019). Effects of a six-week period of congested match play on plasma volume variations, hematological parameters, training workload and physical fitness in elite soccer players. PLoS ONE 14:e0219692. doi: 10.1371/journal.pone. 0219692

Sandbakk, Ø., and Holmberg, H. C. (2017). Physiological capacity and training routines of elite cross-country skiers: approaching the upper limits of human endurance. Int. J. Sports Physiol. Perform. 12, 1003-1011. doi: 10.1123/ijspp.2016-0749

Scott, D., and Lovell, R. (2018). Individualisation of speed thresholds does not enhance the dose-response determination in football training. J. Sports Sci. 36, 1523-1532. doi: 10.1080/02640414.2017.1398894

Tangalos, C., Robertson, S. J., Spittle, M., and Gastin, P. B. (2015). Predictors of individual player match performance in junior Australian Football. Int. J. Sports Physiol. Perform. 10, 853-859. doi: 10.1123/ijspp.2014-0428

Timpka, T., Périard, J. D., Spreco, A., Dahlström, Ö., Jacobsson, J., Bargoria, V., et al. (2020). Health complaints and heat stress prevention strategies during taper as predictors of peaked athletic performance at the 2015 World Athletics Championship in hot conditions. J. Sci. Med. Sport. 23, 336-341. doi: 10.1016/j.jsams.2019.10.024

Tønnessen, E., Hem, E., Leirstein, S., Haugen, T., and Seiler, S. (2013). Maximal aerobic power characteristics of male professional soccer players, 1989-2012. Int. J. Sports Physiol. Perform. 8, 323-329. doi: 10.1123/ijspp. 8.3.323

Vachon, A., Berryman, N., Mujika, I., Paquet, J., Bosquet, L., Vachon, A., et al. (2020). Effects of tapering on neuromuscular and metabolic fitness in team sports : a systematic review and meta-analysis. Eur. J. Sport Sci. doi: 10.1080/17461391.2020.1736183. [Epub ahead of print].

Van Damme, R., Wilson, R. S., Vanhooydonck, B., and Aerts, P. (2002). Performance constraints in decathletes. Nature 415, 755-756. doi: $10.1038 / 415755 b$

Vescovi, J. D., and Falenchuk, O. (2019). Contextual factors on physical demands in professional women's soccer: female Athletes in Motion study. Eur. J. Sport Sci. 19, 141-146. doi: 10.1080/17461391.2018.1491628

Wang, C., Vargas, J. T., Stokes, T., Steele, R., and Shrier, I. (2020). Analyzing activity and injury: lessons learned from the acute:chronic workload ratio. Sports Med. 50, 1243-1254. doi: 10.1007/s40279-020-01280-1

Zernicke, R., and Whiting, W. C. (2008). "Mechanisms of Musculoskeletal Injury" in Biomechanics in Sport: Performance Enhancement and Injury Prevention, ed Vladimir M. Zatsiorsky (London: Blackwell Science Ltd.), 507-522. doi: 10.1002/9780470693797.ch24

Conflict of Interest: The authors declare that the research was conducted in the absence of any commercial or financial relationships that could be construed as a potential conflict of interest.

Copyright (c) 2020 Boullosa, Casado, Claudino, Jiménez-Reyes, Ravé, CastañoZambudio, Lima-Alves, de Oliveira, Dupont, Granacher and Zouhal. This is an open-access article distributed under the terms of the Creative Commons Attribution License (CC BY). The use, distribution or reproduction in other forums is permitted, provided the original author(s) and the copyright owner(s) are credited and that the original publication in this journal is cited, in accordance with accepted academic practice. No use, distribution or reproduction is permitted which does not comply with these terms. 